\title{
Pengaruh Kualitas Informasi, Kualitas Sistem Dan Regulasi Pemerintah Terhadap Implementasi E-Procurement Pada Kantor Dinas Pekerjaan Umum Kota Bitung
}

\author{
Rizal M. R. Sompotan ${ }^{1}$, Silvya L. Mandey ${ }^{2}$, Ivonne S. Saerang ${ }^{2}$ \\ ${ }^{1}$ Mahasiswa Progam Studi Magister Manajemen Fakultas Ekonomi Dan Bisnis \\ ${ }^{2}$ Progam Studi Magister Manajemen Fakultas Ekonomi Dan Bisnis \\ Universitas Sam Ratulangi, Manado \\ Universitas Sam Ratulangi, Manado
}

Received: 04 Januari 2021; Revised: 26 Februari 2021; Accepted: 28 April 2021

DOI: http://dx.doi.org/10.37905/aksara.7.2.605-618.2021

\begin{abstract}
Abstrak
Penelitian ini mengambil lokasi di Dinas Pekerjaan Umum Kota Bitung dan Waktu peneltian bulan Desember 2020 - Maret 2021. Jenis penelitian adalah penelitian kuantitatif yang menguji hipotesa yang berupa hubungan atau pengaruh antar variabel. Di dalam penelitian ini pengaruh kualitas informasi, kualitas system dan regulasi pemerinah sebagai variabel independen dan implementasi eprocurement sebagai variable dependen. Pada Pemerintah Daerah Kota Bitung. Variabel penelitian terdiri atas variabel independen yakni kualitas informasi kualitas sistem, regulasi pemerintah dan variable dependen yakni implementasi eprocurement yang berhubungan dengan kemanfaatan eprocurement bagi penyedia jasa demi memujudkan tranparansi dan akuntabilitas pengadaan barang dan jasa di Kota Bitung. Analisis yang digunakan adalah analisis regresi berganda. Hasil penelitian menunjukkan bahwa terdapat pengaruh yang signifikan antara kualitas informasi dengan e-procurement dan terdapat pengaruh yang signifikan antara kualitas sistem dengan $e$ - procurement.
\end{abstract}

Kata Kunci: kualitas informasi, regulasi pemerintah, implementasi, EProcuement

\begin{abstract}
This research took place at the Public Works Office of Bitung City and the time of the study was December 2020 - March 2021. This type of research is a quantitative study that tests hypotheses in the form of relationships or influences between variables. In this study, the influence of information quality, system quality and government regulations as the independent variable and the implementation of eprocurement as the dependent variable. In the Regional Government of Bitung City. The research variables consisted of independent variables, namely the quality of system quality information, government regulations and the dependent variable, namely the implementation of e-procurement related to the benefits of eprocurement for service providers in order to achieve transparency and accountability for the procurement of goods and services in Bitung City. The
\end{abstract}


analysis used is multiple regression analysis. The results showed that there was a significant influence between the quality of information and e-procurement and there was a significant influence between the quality of the system and $e$ procurement.

Keywords: information quality, government regulation, implementation, EProcurement

\section{PENDAHULUAN}

Kualitas memiliki banyak makna bagi setiap orang sehingga pengertian kualitas akan dapat berbeda, hal tersebut disebabkan karena kualitas memiliki banyak kriteria dan sangat tergantung pada konteksnya. Salah satu pengertian kualitas dikemukakan oleh Goetsch \& Davis dalam Hessel Nogi S. Tangkilisan (2007:209) berdasarkan sudut pandangnya sebagai berikut: "Kualitas merupakan suatu kondisi dinamis yang berhubungan dengan produk, jasa, manusia, proses, dan lingkungan yang memenuhi atau melebihi harapan." Berdasarkan pengertian tersebut penulis menyimpulkan bahwa kualitas adalah keadaan yang dapat memenuhi atau lebih dari yang diharapkan atas suatu produk, jasa, manusia, proses, dan lingkungan. Bagi suatu perusahaan, kualitas dari berbagai hal perlu diperhatikan baik itu kualitas produk, kualitas jasa/pelayanan, kualitas fasilitas perusahaan, kualitas pegawai, maupun kualitas sistem informasi. Berbagai hal yang dimiliki oleh perusahan apabila berkualitas maka dapat memberikan nilai tambah yang menguntungkan bagi perusahaan. 17 Definisi Sistem Informasi Dalam menjalankan kegiatan usahanya, perusahaan membutuhkan berbagai informasi untuk menjalankan kegiatannya dengan efektif dan efisien. Informasi yang dibutuhkan adalah informasi yang relevan, akurat, dan tepat waktu, untuk menghasilkan informasi yang berkualitas maka dibuatlah sistem informasi. Sistem informasi memungkinkan perusahaan untuk memperoleh berbagai informasi yang dapat menyediakan informasi untuk pengambilan keputusan saat ini dan masa depan serta untuk mendukung strategi bersaing perusahaan. Informasi yang menjadi hasil dari sebuah sistem informasi merupakan aset yang sangat berharga dalam meningkatkan operasi yang efisien dan manajemen yang efektif dari perusahaan. Menurut Azhar Susanto (2013:52) sistem informasi sebagai berikut: Sistem informasi adalah kumpulan dari sub sistem baik phisik maupun non phisik yang saling berhubungan satu sama dan bekerja sama secara harmonis untuk mencapai satu tujuan yaitu mengolah data menjadi informasi yang berguna. Laudon dalam Azhar Susanto (2013:52) menyatakan bahwa: Sistem informasi merupakan komponen-komponen yang saling berhubungan dan bekerja sama untuk mengumpulkan, memproses, menyimpan dan menyebarkan informasi untuk mendukung pengambilan keputusan, koordinasi, pengendalian, dan untuk memberikan gambaran aktivitas didalam perusahaan. Menurut McKeown dalam Azhar Susanto (2013:52) sebagai berikut: "Sistem informasi merupakan gabungan dari komputer dan user yang mengelola perubahan data menjadi informasi serta menyimpan data dan informasi tersebut." 18 Menurut O'Brian dalam Yakub (2012:17) sistem informasi sebagai berikut: Sistem informasi (information system) merupakan kombinasi teratur dari orang-orang, perangkat keras (hardware), perangkat lunak (software), jaringan komunikasi, dan sumber daya data yang 
mengumpulkan, mengubah, dan menyebarkan informasi dalam sebuah organisasi. Sedangkan menurut Jogiyanto dalam Yakub (2012:17): Sistem informasi adalah suatu sistem di dalam suatu organisasi yang mempertemukan kebutuhan pengolahan data transaksi harian, mendukung operasi, bersifat manajerial dan kegiatan strategi dari suatu organisasi serta menyediakan pihak luar tertentu dengan laporan-laporan yang diperlukan. Berdasarkan beberapa pengertian sistem informasi diatas, dapat disimpulkan bahwa sistem informasi merupakan kombinasi dari teknologi informasi dan orang yang menggunakan teknologi itu dalam melakukan aktivitasnya untuk mendukung operasional perusahaan dan membantu manajemen dalam mengambil keputusan. Dengan sistem informasi membantu perusahaan dapat menjalankan kegiatan perusahaan secara efektif dan efisien.

\section{Komponen Sistem Informasi}

Sistem infomasi memiliki beberapa komponen didalamnya. Dalam suatu sistem informasi apabila salah satu unsur tidak dipenuhi, maka sistem informasi tersebut mungkin tidak akan terwujud. Komponen-komponen sistem informasi yang terintegrasi berfungsi untuk mendukung dan meningkatkan operasi seharihari perusahaan, juga menyediakan kebutuhan informasi untuk pemecahan masalah dan pengambilan keputusan manajemen. 19 Menurut Abdul Kadir (2003:70) komponen sistem informasi terdiri dari: 1. Perangkat keras (hardware) 2. Perangkat lunak (software) atau program 3. Prosedur 4. Orang 5. Basis data (database) 6. Jaringan komputer dan komunikasi data. Adapun menurut Azhar Susanto (2013:58) mengenai komponen sistem informasi dengan menambahkan pengelompokkan lainnya terdiri dari: 1. Perangkat keras (Hardware) 2. Perangkat lunak (Software) 3. Manusia (Brainware) 4. Prosedur (Procedure) 5. Basisdata (Database) 6. Jaringan komunikasi (Communication Network) Salah satu pengelompokkan lainnya adalah 1. Data (Data) 2. Orang-orang (Brainware) 3. Aktivitas (Activities) 4. Jaringan (Network) 5. Teknologi (Technology). Adapun penjelasan dari komponen sistem informasi tersebut adalah: 1. Perangkat keras (Hardware) Mencakup peranti-peranti fisik seperti komputer, monitor, mouse, dan printer. 2. Perangkat lunak (Software) Sekumpulan instruksi yang memungkinkan perangkat keras untuk dapat memproses data. 3. Manusia (Brainware) Semua pihak yang bertanggung jawab sebagai sponsor sistem informasi (system owner), pengguna sistem (system user), perancang sistem (system designer) dan pengembang sistem informasi (sistem development). 20 4. Prosedur (Procedure) Sekumpulan aturan yang dipakai untuk mewujudkan pemrosesan data dan pembangkitan keluaran yang dikehedaki. 5 . Basisdata (Database) Sekumpulan tabel, hubungan, dan Iain-lain yang berkaitan dengan penyimpanan data. 6. Jaringan komunikasi (Communication Network) Sistem penghubung yang memungkinkan sumber (resources) dipakai secara bersama atau diakses oleh sejumlah pemakai. Adapun penjelasan komponen sistem informasi pada pengelompokkan lainnya diatas yaitu: 1. Data (Data) Deskripsi tentang benda, kejadian, aktivitas, dan transaksi yang tidak mempunyai makna dan tidak berpengaruh langsung secara langsung kepada pemakainya atau disebut juga sebagai sekumpulan fakta mentah dalam isolasi. 2. Orang-orang (Brainware) Semua pihak yang bertangung jawab dalam pengembangan sistem informasi, pemrosesan, dan pengunan keluaran sistem informasi. 3. Aktivitas (Activities) Sekumpulan aturan atau tahapan-tahapan untuk membuat, memakai, memproses 
dan mengolah sistem informasi ataupun hasil keluaran dari sistem informasi tersebut. 4. Jaringan (Network) Sistem penghubung yang memungkinkan suatu sumber dipakai secara bersama-sama, baik pada waktu dan tempat bersamaan ataupun berbeda. 5. Teknologi (Technology) Teknologi merupakan "tool box" dalam sistem informasi, Teknologi digunakan untuk menerima input, menjalankan model, menyimpan dan mengakses data, menghasilkan dan mengirimkan keluaran, dan membantu pengendalian dari sistem secara keseluruhan.

Pada prakteknya, belum tentu semua sistem informasi mencakup keseluruhan komponen-komponen tersebut. Sebagai contoh, sistem informasi pribadi yang hanya melibatkan seorang pengguna dan sebuah komputer dan tidak selalu melibatkan fasiltas jaringan dan komunikasi, berbeda dengan sistem informasi grup kerja (workgroup information system) yang melibatkan sejumlah orang dan sejumlah komputer, memerlukan sarana jaringan dan komunikasi. Model Kesuksesan Sistem Informasi Dalam penerapan sebuah sistem informasi untuk pelaksanaan kegiatan perusahaan yang paling penting apakah perusahaan mendapatkan kesuksesan penerapan sistem atau kegagalan penerapan sistem. Mengukur kualitas dari suatu sistem informasi bukanlah suatu hal yang mudah, hal ini disebabkan tidak adanya kriteria yang menjadi standar dalam menentukan kualitas sistem informasi itu sendiri. Pengukuran kualitas sistem dapat dilakukan dengan melihat efektifitas suatu sistem informasi yang dijalankan di dalam perusahaan. Pengukur-pengukur kualitas sistem informasi menurut Bailey dan Pearson dalam Jogiyanto (2007:14) terdiri dari: 1. Kenyamanan akses 2. Keluwesan sistem 3. Integritas sistem 4. Waktu respon. Penjelasan mengenai pengukuran kualitas sistem informasi diatas adalah sebagai berikut: 1. Kenyamanan akses, berarti sistem informasi mudah dipelajari dan mudah dipahami pada awal penggunaannya, kemudahan dalam pengoperasian sistem akan memudahkan pengguna dalam menggunakan sistem tersebut, dan sistem informasi sesuai dengan kebutuhan pengguna. 2. Keluwesan sistem, sistem yang luwes atau fleksibel adalah sistem yang mempunyai kemampuan untuk mencapai suatu tujuan lewat sejumlah cara yang berbeda. Karakteristik penting dalam mencapai keluwesan suatu sistem adalah bahwa sistem harus dapat menyesuaikan diri dengan 27 keinginan pengguna, dan bukan pengguna yang harus menyesuaikan diri dengan kerangka sistem yang telah ditetapkan oleh perancang sistem ataupun sistem informasi dapat disesuaikan dengan proses bisnis dan kegiatan. Dengan kata lain, program yang ada dapat ditambah atau dikurangi sesuai dengan keperluan sehingga sistem informasi berjalan sesuai fungsinya. 3. Integritas sistem, sistem dapat diakses tanpa menyulitkan pengguna dan tidak dapat diakses oleh pihak yang tidak berkepentingan. Selain itu, integritas sistem dapat dinilai dari kemampuan sistem menemukan kesalahan. 4. Waktu respon, waktu yang dibutuhkan oleh sistem untuk merespon input dan tepatnya pengolahan input untuk menghasilkan data atau informasi. Kualitas sistem informasi menjadi hal penting untuk diukur untuk mengetahui kepuasan pengguna sistem informasi. Pengguna sistem informasi akuntansi akan menggunakan sistem informasi dan merasa puas apabila sistem tersebut mempercepat dan memudahkan pekerjaan, fleksibel dengan kebutuhan pengguna, mudah diakses dan dapat menghasilkan informasi dengan cepat. Ada beberapa pengertian e-Government yang dikemukakan para ahli, diantaranya: The 
World Bank Group mendefinisikan e-Government sebagai berikut: e-Government berhubungan dengan penggunaan teknologi informasi (seperti wide area network, Internet dan mobile computing) oleh organisasi pemerintahan yang mempunyai kemampuan membentuk hubungan dengan warga Negara, bisnis dan organisasi lain dalam pemerintahan. (The World Bank Group,2001 :3) Ditujukan untuk membangun hubungan antara organisasi pemerintahan dengan warga Negara. Hal ini penting dilakukan oleh organisasi pemerintahan sebagai organisasi sektor publik dalam usahanya untuk mendapatkan legitimasi dari segenap warga Negara yang menggunakan layanannnya. Menyediakan akses kepada warga Negara semua detail aktifitas layanan sektor publik. Ini terutama berhubungan dengan keadaan yang dapat dipertangung jawabkan (accountable). Proses transformasi dan informasi mendukung tersedianya aliran informasi dari organisasi pemerintahan kepada warga negaranya, dan mereka cukup percaya untuk menggunakan layanan tersebut. Adapun definisi lain (Zweers and Planque, 2001): Berhubungan dengan penyedia informasi, layanan atau produk yang disiapkan secara elektronis, dengan dan oleh pemerinah, tidak terbatas tempat dan waktu, menawarkan nilai lebih untuk partisipasi pada semua kalangan. (Zweers and Planque, 2001) Era reformasi di Indonesia sedikit banyak cukup mempengaruhi kehidupan, terutama pola pikir masyarakat dan pemerintah, sehingga munculah sistem pelayanan oleh pemerintah kepada masyarakat berbasis e-Government. Menurut UNDP definisi $e$-Government sebagai berikut: E-Government is the application of Information and Tecnology Communication (ICT) by government agencies (e-Government adalah aplikasi teknologi informasi dan komunikasi dari agen pemerintah) (dalam Indrajit, 2004:2).

\section{METODE PENELITIAN}

Penelitian ini mengambil lokasi di Dinas Pekerjaan Umum Kota Bitung dan Waktu peneltian bulan Desember 2020 - Maret 2021. Jenis penelitian adalah penelitian kuantitatif yang menguji hipotesa yang berupa hubungan atau pengaruh antar variabel. Di dalam penelitian ini pengaruh kualitas informasi, kualitas system dan regulasi pemerinah sebagai variabel independen dan implementasi eprocurement sebagai variable dependen. Pada Pemerintah Daerah Kota Bitung. Penelitian ini menggunakan kuesioner dalam pengumpulan datanya, maka sumber datanya disebut responden yaitu orang yang merespon atau menjawab pertanyaan peneliti, baik secara tertulis maupun secara lisan (Arikunto, 1998), dalam hal ini yang menjadi responden (subyek penelitian) adalah penyedia barang dan jasa. Jenis data yang digunakan adalah data kualitatif yang berasal dari jawaban responden atas kuesioner yang dikuantifikasikan menggunakan skala Likert. Tingkat analisis penelitian ini adalah individu karena yang ingin diketahui adalah manfaat pelaksanaan e-procurement yang dirasakan secara individu. Variabel penelitian terdiri atas variabel independen yakni kualitas informasi kualitas sistem, regulasi pemerintah dan variable dependen yakni implementasi e-procurement yang berhubungan dengan kemanfaatan eprocurement bagi penyedia jasa demi memujudkan tranparansi dan akuntabilitas pengadaan barang dan jasa di Kota Bitung. Berikut dijelaskan definisi operasional tiap-tiap variabel penelitian.

1. Kualitas Informasi (X1) Variabel ini menggambarkan isu konten dari sistem eprocurementatau seberapa baik keluaran dari sistem eprocurement. Indikator 
pengukuran pada konstruksi ini diadopsi indikator kesuksesan e-commerce yang telah didefinisikan oleh DeLone \& McLean (2003), penelitian Wang \& Liao (2008) yang menggunakan Model Kesuksesan Sistem Informasi DeLone \& McLean (2003) pada sistem e-government, dan penelitian Lin (2007) yang juga menggunakan Model Kesuksesan Sistem Informasi DeLone \& McLean (2003) pada online learning. Indikator tersebut adalah kelengkapan, mudah dimengerti, relevansi (DeLone \& McLean, 2003), ketepatan waktu (Wang \& Liao, 2008), dan keakuratan (Lin, 2007). Pengukuran variabel dengan instrumen kuesioner menggunakan skala Likert 5 poin: sangat tidak setuju (skor 1), tidak setuju (skor 2), raguragu (skor 3), setuju (skor 4), sangat setuju (skor 5).

2. Kualitas Sistem (X2) Pengukuran terhadap sistem pengolahan informasi itu sendiri. Indikator pengukuran pada konstruksi ini diadopsi indikator kesuksesan e-commerce yang telah didefinisikan oleh DeLone\& McLean (2003). Indikator tersebut adalah kehandalan, response time, dan mudah digunakan (DeLone \& McLean, 2003). Pengukuran variabel dengan instrumen kuesioner menggunakan skala Likert 5 poin: sangat tidak setuju (skor 1), tidak setuju (skor 2), raguragu (skor 3), setuju (skor 4), sangat setuju (skor 5).

3. Regulasi Pemerintah (X3) Regulasi pemerintah merupakan hal yang harus dipatuhi dalam pengadaan publik. Indikator pengukuran pada konstruksi ini diadopsi dari penelitian Bernroider \& Schmollerl (2013) dan penelitian Wilson $\&$ Rodgers (2004). Indikator tersebut adalah paksaan untuk patuh pada regulasi (Bernroider \& Schmollerl, 2013) dan (Wilson \& Rodgers, 2004), serta tekanan yang diberikan oleh penyedia lain dan pemerintah (Wilson \& Rodgers, 2004). Pengukuran variabel dengan instrumen kuesioner menggunakan skala Likert 5 poin: sangat tidak setuju (skor 1), tidak setuju (skor 2), ragu-ragu (skor 3), setuju (skor 4), sangat setuju (skor 5).

4. Implementasi e-procurement (Y) Manfaat yang Dirasakan Pengukuran manfaat yang dirasakan tergantung pada tujuan serta konteks penelitian. Untuk kasus eprocurement yang pengguna utamanya adalah penyedia barang/jasa, indikator pengukuran manfaat yang dirasakan merupakan manfaat e-procurement bagi penyedia. sistem e-procurement di Indonesia menekankan terhadap transparansi untuk pemberantasan korupsi. Indikator manfaat berupa transparansi ini akan menjadi pengukuran manfaat yang dirasakan oleh penyedia barang/jasa. Pengukuran variabel dengan instrumen kuesioner

menggunakan skala Likert 5 poin: sangat tidak setuju (skor 1), tidak setuju (skor 2), ragu-ragu (skor 3), setuju (skor 4), sangat setuju (skor 5).

\section{Analisis Regresi Linier Berganda}

Analisis regresi berganda bertujuan untuk memprediksi berapa besar kekuatan pengaruh variabel independen terhadap variabel dependen. Persamaan regresi yang digunakan dalam penelitian ini diasumsikan linier dan diuji dengan tingkat signifikansi sebesar 0,05 . Model persamaan regresinya adalah:

$\mathrm{Y}=\boldsymbol{\beta 0}+\boldsymbol{\beta 1 X 1}+\boldsymbol{\beta} 2 \mathrm{X} 2+\beta 3 \mathrm{X3}+\mathrm{e}$

Keterangan:

$\mathrm{Y}=$ Implementasi e-procurement

$\beta 0=$ intersep

$\beta 1, \beta 2, \beta 3=$ koefisien regresi 
$\mathrm{X} 1=$ kualitas informasi

$\mathrm{X} 2$ = kualitas system

$\mathrm{X} 3=$ regulasi pemerintah

$\mathrm{e}=$ variabel pengganggu

Langkah-langkah untuk menguji pengaruh variabel independen, dilakukan dengan uji Adjusted $\mathrm{R}^{2}$, uji model (uji F), dan uji parsial (uji t).

\section{Results and Discussion}

Kantor Dinas Pekerjaan Umum Kota Bitung sebagai penyelenggaraan urusan pemerintah bidang pekerjaan umum, pembangunan infrastrukur dan perumahan untuk daerah Bitung, terkait dengan wewenang tersebut, maka melalui kantor ini beberapa surat perizinan diproses. Beberapa surat tersebut seperti Izin Pemanfaatan Ruang (IPR) dan Izin Mendirikan Bangunan (IMB).

\section{Layanan Pengadaan Secara Elektronika (LPSE) Kota Bitung}

Kantor LPSE Kota Bitung proyek pemerintahan terkait pembangunan, renovasi, hingga pengadaan dilingkungan kerja yang dilakukan. Tugas utama dari LPSE adalah memfasilitasi penyelenggaraan layanan pengadaan barang dan jasa pemerintah secara elektronik. Sehingga fungsi LPSE ini sendiri yaitu pengelolaan LPSE dan infrastrukturnya, pelaksanaan registrasi dan verifikasi pengadaan dan lelang melalui LPSE, penyusunan program kegiatan, ketatausahaan, evaluasi dan pelaporan pengelolaan pengadaan barang dan jasa secara elektronik dan lainnya. LPSE ini juga memastikan semua prosesnya berjalan secara terbuka, transparansi dan akuntabel.

Hasil Uji Instrumen Penelitian

Uji Validitas Item Pernyataan

Tabel 5.1. Hasil Uji Validitas Kuesioner

\begin{tabular}{|c|c|c|c|c|}
\hline \multirow{4}{*}{ Variabel } & \multirow{3}{*}{ Pernyataan } & \multicolumn{3}{|c|}{$\begin{array}{c}\text { Korelasi (r) } \\
\text { (Uji Validitas) }\end{array}$} \\
\cline { 3 - 5 } & & Nilai & $\begin{array}{c}\text { Nilai } \\
\mathbf{r} \\
\text { tabel }\end{array}$ & Status \\
\hline \multirow{4}{*}{ XI } & X1.1.1 & 0.67 & 0.361 & Valid \\
\cline { 2 - 5 } & X1.1.2 & 0.702 & 0.361 & Valid \\
\cline { 2 - 5 } & X1.1.3 & 0.834 & 0.361 & Valid \\
\cline { 2 - 5 } & $\mathrm{X} 1.1 .4$ & 0.861 & 0.361 & Valid \\
\cline { 2 - 5 } & $\mathrm{X} 1.1 .5$ & 0.816 & 0.361 & Valid \\
\hline \multirow{4}{*}{ X2 } & $\mathrm{X} 2.1 .1$ & 0.699 & 0.361 & Valid \\
\cline { 2 - 5 } & $\mathrm{X} 2.1 .2$ & 0.819 & 0.361 & Valid \\
\cline { 2 - 5 } & $\mathrm{X} 2.1 .3$ & 0.852 & 0.361 & Valid \\
\cline { 2 - 5 } & $\mathrm{X} 2.1 .4$ & 0.846 & 0.361 & Valid \\
\cline { 2 - 5 } & $\mathrm{X} 2.1 .5$ & 0.79 & 0.361 & Valid \\
\hline \multirow{4}{*}{ X3 } & $\mathrm{X} 3.1 .1$ & 0.817 & 0.361 & Valid \\
\cline { 2 - 5 } & $\mathrm{X} 3.1 .2$ & 0.724 & 0.361 & Valid \\
\cline { 2 - 5 } & $\mathrm{X} 3.1 .3$ & 0.858 & 0.361 & Valid \\
\cline { 2 - 5 } & & & &
\end{tabular}




\begin{tabular}{|c|c|c|c|c|}
\hline \multirow{4}{*}{} & X3.1.4 & 0.883 & 0.361 & Valid \\
\cline { 2 - 5 } & X3.1.5 & 0.792 & 0.361 & Valid \\
\hline \multirow{4}{*}{$\mathrm{Y}$} & Y1 & 0.741 & 0.361 & Valid \\
\cline { 2 - 5 } & Y2 & 0.751 & 0.361 & Valid \\
\cline { 2 - 5 } & Y3 & 0.818 & 0.361 & Valid \\
\cline { 2 - 5 } & Y4 & 0.723 & 0.361 & Valid \\
\cline { 2 - 5 } & Y5 & 0.582 & 0.361 & Valid \\
\hline
\end{tabular}

Dari hasil uji validitas didapat 4 (empat) output, yang pertama adalah variabel Kualitas Informasi (X1), kedua variabel Kualitas Sistem (X2), ketiga Regulasi Pemerintah (X3), dan yang keempat variabel Implementasi E Procurement (Y).

Dari output tersebut dapat diketahui nilai korelasi antara tiap item dengan skor total item. Nilai korelasi ini dibandingkan dengan $r$ tabel, $r$ tabel dicari pada signifikansi 0,05 dengan uji 2 sisi dan jumlah data $(n)=47$, maka didapat $r$ tabel sebesar 0,361 (lihat pada lampiran).

Untuk variabel (X1) Kualitas Informasi keseluruhan item dinyatakan valid, karena memiliki hasil nilai pengujian diatas $0.361 \mathrm{r}$ tabel yang menjadi syarat validitas.

Untuk variabel (X2) Kualitas Sistem keseluruhan item dinyatakan valid, karena memiliki hasil nilai pengujian diatas $0.361 \mathrm{r}$ tabel yang menjadi syarat validitas.

Untuk variabel (X3) Regulasi Pemerintah item dinyatakan valid, karena memiliki hasil nilai pengujian diatas $0.361 \mathrm{r}$ tabel yang menjadi syarat validitas.

Untuk variabel (Y) Implementasi E - Procurement keseluruhan item dinyatakan valid, karena memiliki hasil nilai pengujian diatas $0.361 \mathrm{r}$ tabel yang menjadi syarat validitas.

\section{Uji Reliabilitas Kuesioner}

Tabel 5.2. Hasil Uji Reliabilitas Kuesioner

\begin{tabular}{|c|c|c|c|c|c|c|}
\hline \multirow{2}{*}{ Variabel } & \multirow{2}{*}{ Pernyataan } & \multicolumn{3}{|c|}{$\begin{array}{c}\text { Korelasi (r) } \\
\text { (Uji Validitas) }\end{array}$} & \multicolumn{2}{|c|}{$\begin{array}{l}\text { Cronbach's Alpha } \\
\text { (Uji Reliabilitas) }\end{array}$} \\
\hline & & Nilai & $\begin{array}{c}\text { Nilai } \mathbf{r} \\
\text { tabel }\end{array}$ & Status & Nilai & Status \\
\hline \multirow{5}{*}{ XI } & $\mathrm{X} 1.1 .1$ & 0.67 & 0.361 & Valid & \multirow{5}{*}{0.836} & \multirow{5}{*}{ Reliabel } \\
\hline & $\mathrm{X} 1.1 .2$ & 0.702 & 0.361 & Valid & & \\
\hline & $\mathrm{X} 1.1 .3$ & 0.834 & 0.361 & Valid & & \\
\hline & $\mathrm{X} 1.1 .4$ & 0.861 & 0.361 & Valid & & \\
\hline & $\mathrm{X} 1.1 .5$ & 0.816 & 0.361 & Valid & & \\
\hline \multirow{5}{*}{$\mathrm{X} 2$} & $\mathrm{X} 2.1 .1$ & 0.699 & 0.361 & Valid & \multirow{5}{*}{0.857} & \multirow{5}{*}{ Reliabel } \\
\hline & $\mathrm{X} 2.1 .2$ & 0.819 & 0.361 & Valid & & \\
\hline & $\mathrm{X} 2.1 .3$ & 0.852 & 0.361 & Valid & & \\
\hline & $\mathrm{X} 2.1 .4$ & 0.846 & 0.361 & Valid & & \\
\hline & $\mathrm{X} 2.1 .5$ & 0.79 & 0.361 & Valid & & \\
\hline
\end{tabular}




\begin{tabular}{|c|c|c|c|c|c|c|}
\hline \multirow{5}{*}{ X3 } & X3.1.1 & 0.817 & 0.361 & Valid & \multirow{5}{*}{0.873} & \multirow{5}{*}{ Reliabel } \\
\hline & X3.1.2 & 0.724 & 0.361 & Valid & & \\
\hline & X3.1.3 & 0.858 & 0.361 & Valid & & \\
\hline & X3.1.4 & 0.883 & 0.361 & Valid & & \\
\hline & X3.1.5 & 0.792 & 0.361 & Valid & & \\
\hline \multirow{5}{*}{$\mathrm{Y}$} & $\mathrm{Y} 1$ & 0.741 & 0.361 & Valid & \multirow{5}{*}{0,765} & \multirow{5}{*}{ Reliabel } \\
\hline & $\mathrm{Y} 2$ & 0.751 & 0.361 & Valid & & \\
\hline & $\mathrm{Y3}$ & 0.818 & 0.361 & Valid & & \\
\hline & $\mathrm{Y} 4$ & 0.723 & 0.361 & Valid & & \\
\hline & Y5 & 0.582 & 0.361 & Valid & & \\
\hline
\end{tabular}

Dari hasil Tabel 5.2. Pengujian reliabilitas untuk 20 item pernyataan, terlihat jelas bahwa dari 20 item pernyataan yang sudah diuji menggunakan program SPSS 22 for Windows semuanya reliabel sebab memiliki nilai cronbach "s alpha if item deleted sudah diatas 0,60 , hal ini dapat diperincikan dengan penjelasan bahwa untuk Kualitas Informasi dengan 5 item pernyataan semua indikator pertanyaan dalam variabel Kualitas Informasi sudah reliabel karena nilai cronbach's alpha sebesar 0,836

Kemudian untuk variabel Kualitas Sistem dengan 5 item pernyataan, semua item reliabel dengan nilai cronbach's alpha sebesar 0,857, untuk variabel Regulasi Pemerintah dengan 5 item pernyataan reliabel karena nilai cronbach's alpha sebesar 0,873, sedangkan untuk variabel Implementasi E - Procurement dengan 5 item pernyataan reliabel karena memiliki nilai cronbach's alpha sebesar 0,765.

\section{Uji Normalitas}

Tabel 5.3. Hasil Uji Normalitas

One-Sample Kolmogorov-Smirnov Test

\begin{tabular}{|ll|r|}
\hline & & \multicolumn{2}{|c|}{ Unstandardized Residual } \\
\hline $\mathrm{N}$ & & 47 \\
Normal Parameters ${ }^{\mathrm{a}, \mathrm{b}}$ & Mean & .0000000 \\
& Std. & 1.80038324 \\
Most Extreme & Deviation & .087 \\
Differences & Absolute & .087 \\
& Positive & -.076 \\
Test Statistic & Negative & .087 \\
Asymp. Sig. (2-tailed) & & $.200^{\mathrm{c}, \mathrm{d}}$ \\
\hline
\end{tabular}

Uji normalitas yang digunakan dalam pembahasan ini adalah uji Kolmogorov Smirnov, dimana Analisis statistic dengan cara ini digunakan untuk mendeteksi dan mengetahui apakah data tersebut berdistribusi normal. Kriteria yang digunakan dalam Kolmogorov Smirnov Test adalah sebagai berikut:

1) Angka signifikansi (SIG) $>0,05$, maka data berdistribusi normal

2) Angka signifikansi $(\mathrm{SIG})<0,05$, maka data tidak berdistribusi normal 
Berdasarkan tabel 5 diatas dapat dilihat bahwa nilai Asymp.Sig. (2-tailed) memiliki nilai signifikan diatas 0,05 yang berarti seluruh variabel data yang ada memenuhi syarat untuk uji normalitas atau data terdistribusi normal.

\section{Analisis Regresi Linier Berganda}

Berdasarkan data penelitian yang dikumpulkan baik untuk variabel terikat (Y) maupun variabel bebas (X1, X2, X3) yang diolah dengan bantuan program SPSS 22 for Windows, maka diperoleh hasil perhitungan regresi linear berganda sebagai berikut:

Tabel 5.5. Hasil Perhitungan Regresi

\begin{tabular}{|l|r|r|r|r|r|r|r|}
\hline \multirow{3}{*}{ Model } & \multicolumn{2}{|c|}{$\begin{array}{c}\text { Unstandardized } \\
\text { Coefficients }\end{array}$} & $\begin{array}{c}\text { Standardized } \\
\text { Coefficients }\end{array}$ & \multirow{2}{*}{$\mathrm{t}$} & \multicolumn{2}{|c|}{ Sig. } & \multicolumn{2}{|c|}{$\begin{array}{c}\text { Collinearity } \\
\text { Statistics }\end{array}$} \\
\cline { 2 - 4 } \cline { 7 - 9 } & \multicolumn{1}{c|}{$\mathrm{B}$} & $\begin{array}{c}\text { Std. } \\
\text { Error }\end{array}$ & Beta & & & Tolerance & VIF \\
\hline (Constant) & 1.018 & 1.387 & & 0.734 & 0.467 & & \\
X1 & 0.199 & 0.146 & 0.199 & 1.359 & 0.180 & 0.188 & 5.315 \\
\hline X2 & 0.22 & 0.123 & 0.213 & 1.79 & 0.080 & 0.284 & 3.526 \\
X3 & 0.519 & 0.131 & 0.533 & 3.973 & 0.000 & 0.224 & 4.459 \\
\hline
\end{tabular}

Sumber: Data primer yang diolah dengan SPSS 22

Hasil pengolahan dan komputerisasi data dapat ditunjukkan melalui persamaan regresi linier berganda sebagai berikut:

$$
\mathrm{Y}=1.018+0.199 \mathrm{X} 1+0.22 \mathrm{X} 2+0.519 \mathrm{X3}+\mathrm{e}
$$

$\mathrm{a}=1.018$; artinya apabila variabel Kualitas Informasi $\left(\mathrm{X}_{1}\right)$, Kualitas Sistem $\left(\mathrm{X}_{2}\right)$ dan Regulasi Pemerintah $\left(\mathrm{X}_{3}\right)=0$ konstan, maka nilai dari variabel Implementasi $\mathrm{E}$ - Procurement $(\mathrm{Y})=1.018$

$\mathrm{b}_{1}=0.199$; artinya apabila kenaikan variabel Kualitas Informasi $\left(\mathrm{X}_{1}\right)$ sebesar 1 satuan akan menyebabkan kenaikan variabel Implementasi E - Procurement (Y) sebesar 0.199, dengan asumsi variabel Kualitas Sistem $\left(\mathrm{X}_{2}\right)$ dan variabel Regulasi Pemerintah $\left(\mathrm{X}_{3}\right)$ konstan.

$\mathrm{b}_{2}=0.22$; artinya apabila kenaikan variabel Kualitas Sistem $\left(\mathrm{X}_{2}\right)$ sebesar 1 satuan akan menyebabkan kenaikan variabel Implementasi E - Procurement (Y) sebesar 0.22 , dengan asumsi variabel Kualitas Informasi $\left(\mathrm{X}_{1}\right)$ dan variabel Regulasi Pemerintah $\left(\mathrm{X}_{3}\right)$ konstan.

$\mathrm{b}_{3}=0.519$; artinya apabila kenaikan variabel Regulasi Pemerintah $\left(\mathrm{X}_{3}\right)$ sebesar 1 satuan akan menyebabkan kenaikan variabel Implementasi E - Procurement (Y) sebesar 0.519, dengan asumsi variabel Kualitas Informasi $\left(\mathrm{X}_{1}\right)$ dan variabel Kualitas Sistem $\left(\mathrm{X}_{2}\right)$ konstan.

\section{Hasil Koefisien Determinasi}

Tabel 5.6. Hasil Perhitungan $\left(\mathrm{R}^{2}\right)$

Model Summary ${ }^{\mathrm{b}}$

\begin{tabular}{|l|c|r|r|r|}
\hline Model & R & R Square & $\begin{array}{c}\text { Adjusted R } \\
\text { Square }\end{array}$ & $\begin{array}{c}\text { Std. Error of } \\
\text { the Estimate }\end{array}$ \\
\hline 1 & $.898^{\mathrm{a}}$ & .806 & .794 & 1.856 \\
\hline
\end{tabular}

Sumber: Data primer yang diolah dengan SPSS 22 
Dalam ringkasan hasil regresi yang ditunjukkan pada tabel 8 diatas, nilai $\mathrm{R}$ $=0,898$ nilai korelasi ganda mendekati angka 1 artinya terdapat hubungan positif dan kuat antara Kualitas Informasi, Kualitas Sistem dan Regulasi Pemerintah terhadap Implementasi E - Procurement.

Analisis Koefisien determinasi (Adjusted $R^{2}$ ) digunakan untuk mengetahui persentase sumbangan pengaruh variabel independen secara bersama-sama terhadap variabel dependen, hasil analisis determinasi dapat dilihat pada tabel 5.6, dimana $\mathrm{R}^{2}$ mempunyai korelasi sebesar 0,806 atau $80,6 \%$, artinya persentase sumbangan pengaruh variabel independen secara bersamaan yaitu Kualitas Informasi $\left(\mathrm{X}_{1}\right)$, Kualitas Sistem $\left(\mathrm{X}_{2}\right)$ dan Regulasi Pemerintah $\left(\mathrm{X}_{3}\right)$ terhadap Implementasi E - Procurement sebesar $80,6 \%$ sisanya sebesar 19,4\% dipengaruhi oleh variabel - variabel lain yang tidak di teliti dalam penlitian ini.

\subsubsection{Uji Statistik}

Uji $t$ (Parsial)

Pengujian ini untuk melihat sejauh mana pengaruh secara terpisah dari masing-masing variabel bebas (X) terhadap variabel terikat (Y) berdasarkan hasil regresi yang ada pada tabel 9 uji t dilakukan dengan membandingkan nilai t hitung dengan $t$ tabel. Apabila t hitung $>\mathrm{t}$ tabel maka dapat disimpulkan variabel tersebut mempunyai pengaruh yang positif.

Tabel 5.7. Hasil Uji t (Parsial)

\begin{tabular}{|l|r|r|r|r|r|r|r|}
\hline \multirow{2}{*}{ Model } & \multicolumn{2}{|c|}{$\begin{array}{c}\text { Unstandardized } \\
\text { Coefficients }\end{array}$} & $\begin{array}{c}\text { Standardized } \\
\text { Coefficients }\end{array}$ & \multirow{2}{*}{$\mathrm{t}$} & \multirow{2}{*}{ Sig. } & \multicolumn{2}{|c|}{$\begin{array}{c}\text { Collinearity } \\
\text { Statistics }\end{array}$} \\
\cline { 2 - 4 } \cline { 7 - 9 } & $\mathrm{B}$ & $\begin{array}{c}\text { Std. } \\
\text { Error }\end{array}$ & Beta & & & Tolerance & VIF \\
\hline (Constant) & 1.018 & 1.387 & & 0.734 & 0.467 & & \\
X1 & 0.199 & 0.146 & 0.199 & 1.359 & 0.180 & 0.188 & 5.315 \\
\hline X2 & 0.220 & 0.123 & 0.213 & 1.79 & 0.080 & 0.284 & 3.526 \\
X3 & 0.519 & 0.131 & 0.533 & 3.973 & 0.000 & 0.224 & 4.459 \\
\hline
\end{tabular}

Sumber: Data primer yang diolah dengan SPSS 22

\section{PEMBAHASAN}

\section{Pengaruh Kualitas Informasi Terhadap Implementasi E - Procurement.}

Hasil penelitian ini menunjukkan bahwa variabel Kualitas Informasi berpengaruh signifikan terhadap Implementasi E - Procurement Pada Dinas Pekerjaan Umum Kota Bitung. Setiap kenaikan Kualitas Informasi sebesar satu persen akan meningkatkan implementasi e - procurement sebesar 0.199 persen. Hasil penelitian ini dapat dijelaskan bahwa terdapat kepuasan bagi pengguna. Kualitas informasi mengukur kualitas keluaran implementasi e - procurement. Karena Kualitas informasi merupakan faktor penentu penting terhadap kepuasan pengguna. Kualitas informasi menunjukkan hasil dari implementasi e procurement yang berhubungan dengan nilai, manfaat dan relevansi dari informasi yang dihasilkan bagi pengguna sistem, sehingga memberikan informasi yang berkualitas yaitu, lengkap, akurat, up to date dan dapat dipercaya maka seseorang pengguna akan merasa lebih puas dengan informasi yang diperoleh. Kualitas 
informasi dari sistem e-procurement yang bisa digunakan untuk mengaudit barang dan jasa dalam penelitian terbukti mempunyai pengaruh dalam meningkatkan kepercayaan terhadap sistem tersebut. Dalam penelitian ini kualitas informasi yang memadai (sufficiency), informasi bisa diperoleh saat itu juga (currency), informasi yang akurat (accuracy), informasi yang sesuai kebutuhan (usefulness), informasi dalam format yang bisa digunakan (usableness format), informasi yang jelas (accuracy), informasi yang disajikan terpat waktu (timeliness) dan informasi yang handal (reliability). Hasil penelitian ini mengimplikasikan semakin baiknya kualitas informasi yang dihasilkan oleh sistem e-procurement pada Dinas Pekerjaan Umum Kota Bitung maka semakin tinggi kepercayaan pengguna terhadap sistem tersebut. Maka ketika LKPP dan ULP dari setiap instansi pemerintah ingin meningkatkan kepercayaan pengguna terhadap sistem e-procurement maka harus memperbaiki kualitas informasi yang mencakup informasi yang memadai (sufficiency), informasi bisa diperoleh saat itu juga (currency), informasi yang akurat (accuracy), informasi yang sesuai kebutuhan (usefulness), informasi dalam format yang bisa digunakan (usableness format), informasi yang jelas (accuracy), informasi yang disajikan tepat waktu (timeliness) dan informasi yang handal (reliability).

\section{Pengaruh Kualitas Sistem Terhadap Implementasi E - Procurement.}

Hasil penelitian ini menujukan bahwa variabel Kualitas Sistem berpengaruh signifikan terhadap Implementasi $E$ - Procurement Pada Dinas Pekerjaan Umum Kota Bitung. Hal ini mengakibatkan kualitas sistem memiliki pengaruh terhadap implementasi e-procurement pada Dinas Pekerjaan Umum Kota Bitung. Kualitas sistem yang baik didukung oleh kondisi teknologi informasi yang baik pula. Dalam hal ini, agar menghasilkan kualitas sistem LPSE yang baik, harus didukung oleh kondisi perangkat komputer yang baik pula. Karena penggunaan LPSE secara terus menerus untuk input dan output data dan informasi, dibutuhkan suatu alat yang dapat membantu berlangsungnya kegiatan ini tanpa gangguan. Namun, Auditor dalam pertanyaan terbuka banyak yang memberikan saran agar tampilan LPSE lebih user friendly, terutama untuk melaksanakan audit proses pengadaan barang dan jasa. Penelitian Beldad et al. (2012) mengemukakan bahwa trust terhadap websitee-government dipengaruhi oleh faktor individu pengguna dan organisasi pemerintah yang memberikan pelayanan melalui e-government. Faktor individu tersebut adalah kecenderungan seseorang untuk mudah percaya serta sejauhmana pengelaman pengguna dalam menggunakan internet.

\section{PENUTUP}

Adapun kesimpulan dari penelitian ini adalah sebagai berikut :

1. Hasil penelitian menunjukkan bahwa terdapat pengaruh yang signifikan antara kualitas informasi dengan e-procurement. Artinya para penyedia pengadaan barang/jasa memberikan respon yang baik dan jelas terhadap informasi yang diterima dari Dinas Pekerjaan Umum Kota Bitung.

2. Hasil penelitian menunjukkan bahwa terdapat pengaruh yang signifikan antara kualitas sistem dengan e - procurement. Hal ini berarti bahwa kualitas sistem pada Dinas Pekerjaan Umum Kota Bitung terdapat kemudahan menggunakan (ease of use) dan user friendly dengan demikian meningkatkan kepercayaan 
bagi pengguna sistem e-procurement yang terintegrasi dengan baik sehingga dalam implementasi e-procurement memberikan efisiensi dan efektif bagi pengguna.

\section{DAFTAR PUSTAKA}

Setiawan, R., Pio, L., Cavaliere, L., Sankaran, D., Rani, K., Yapanto, L. M., Laskar, N. H., Raisal, I., Christabel, G. J. A., Setiawan, R., Petra, U. K., Airlangga, U., Pio, L., Cavaliere, L., \& Foggia, U. (n.d.). Access to Financial Services and Women Empowerment, through Microfinance eligibility. 1, 841-859.

Alfian. 2015. Pemetaan Jenis dan Resiko Kecurangan Dalam Audit Pengadaan Barang dan Jasa. Jurnal Pengadaan. ISSN:2089-2861. Vol.4, No.1,

Muhammad Insa. 2016. Penerapan Pakta Integritas Pada Pengadaan Barang/Jasa Untuk Mewujudkan Tata Kelola Pemerintah Yang Bersih. Jurnal Ilmu Hukum Vol. 18, No. 3, Desember, 2016, hal 385-401.

Beth, Elodie. 2005. Main Findings of the Forum Workshop on "improving Transparency in Public Procurement". In OECD. Fighting Corruption and promoting Integrity in Public Procurement. Paris. OECD.

BPK RI., 2016. Ikhtisar Hasil Pemeriksaan Semester II. Jakarta Ghozali. Imam. 2013. Aplikasi Analisis Multivariate Dengan Program SPSS Edisi Keempat. Semarang: Badan Penerbit Universitas Diponegoro.

Hehamahua, A. 2011. Pengadaan Barang dan Jasa, Korupsi dan Reformasi.

Birokrasi. http://www.lkpp.go.ig, diakses pada tanggal 12 Maret 2017.

Hernandez, J. R. dan T. Groot. 2007. Corporate Fraud: Preventive Controls Which Lower Corporate Fraud. Amsterdam Research Centre in Accounting.

Huslina, Hersi. 2015. Pengaruh Integritas Aparatur, Kompetensi Aparatur dan Pemanfaatan Teknologi Informasi Terhadap Efektivitas Sistem Pencegahan.

Fraud. Jurnal Magister Akuntansi. Pascasarjana Univ. Syiah Kuala. ISSN: 23020199. hal 55-64.

Jatiningtyas, N. dan Endang, K. 2011. Analisis Faktor-Faktor Yang Mempengurahi Fraud Pengadaan Barang/Jasa Pada Lingkungan Instansi Pemerintah Di Wilayah Semarang. Tesis, Universitas Diponegoro.

Larasati, D. 2011. Development of Contractor Quality Assurance System in Indonesia Construction Procurement, unpublished Doctor of Philosophy dissertation, Graduate School of Engineering, Kochi University of Technology, Kochi, Japan Messah,

Yunita Afliana. 2013. Pengendalian Waktu dan Biaya Pekerjaan Konstruksi Sebagai Dampak Dari Perubahan Desain (Studi Kasus Embung Irigasi Oenaem, Kecamatan Biboki Selatan Kabupaten Timor Tengah Utara).

Jurnal Teknik Sipil Vol. II No. 2, September 2013.

Menezes, F. M., R. Pitchford, dan A. Wait. 2003. Tendering and Bidding for Access: A Regulator's Guide to Auctions. Australian Journal of Management, Vol 28, No 3, hal 345-370. Ogunsanmi, O, E. 2013. Effects of Procurement Related Factors on Construction Project Performance In Nigeria. Ethiopian Journal of Environmental Studies and Management. Vol.6,No.2. 
Pich, Michael T., Loch Christoph H Loch and Meyer de Arnoud. (2002). On Uncertainty, Ambiguity, and Complexity in Project Management. Informs. Management Science, Vol 48. No.8. hal 1008-1023.

Republik Indonesia. 2000. Keputusan Menteri Nomor 18 tahun 2000 tentang Pedoman Pelaksanaan Pengadaan Barang/Jasa Instansi Pemerintah.

Republik Indonesia. 2010. Peraturan Presiden Nomor 54 Tahun 2010 tentang Pengadaan Barang/Jasa Pemerintah.

Schlenker, B.R., Miller, M.L. \& Johnson, R.M, 2009. Moral Indentity, integrity and personal responsibility. In D. Narvaez \& D.K. Lapsey, Personality, identity and character. Cambridge: Cambridge University Press. hal 316-340.

Siahaan, OCH. 2009. Pengaruh Integritas, Obyektivitas, dan Kompetensi terhadap Efektivitas Audit Internal. Tesis-Abstrak. Program Pascasarjana Unifersitas Gajah Mada.

Sugiyono. 2013. Metode Penelitian Bisnis. Alfabeta. Bandung. Setiaji, Bambang. 2004. Panduan Riset Dengan Pendekatan Kuantitatif. Surakarta. Program Pascasarjana UMS, 2004.

Thai, K. V. 2001. Public Procurement Re-examined. Journal of Public Procurement, Vol 1, No 1, hal 9-50.

True, N.F. 1988. Determining the Accuracy of a Cost Estimate. AACE Transaction, T.2.1 - T.2.10. 